\title{
PROPOSING A COMPREHENSIVE PORTFOLIO MANAGEMENT MODEL FOR CONTRACTOR COMPANIES IN CONSTRUCTION INDUSTRY USING MULTI-CRITERIA DECISION-MAKING TECHNIQUES AND FUZZY LOGIC
}

\author{
Hossein Kheyraie ${ }^{1}$, S. Mohammad Mirhosseini ${ }^{2 *}$, and Ehsan Allah Zeyghami ${ }^{3}$ \\ ${ }^{l}$ PhD Candidate, Engineering and Construction Management, Arak Branch, Islamic Azad University, Arak, \\ Iran \\ ${ }^{2}$ Associate Professor, Department of Civil Engineering, Arak Branch, Islamic Azad University, Arak, Iran \\ m-mirhoseini@iau-arak.ac.ir \\ ${ }^{3}$ Associate Professor, Department of Civil Engineering, Arak Branch, Islamic Azad University, Arak, Iran
}

\begin{abstract}
Project portfolio management is an integrated way to achieve the strategic goals of the organization through the evaluation, prioritization, selection and management of projects, plans and other related tasks based on their involvement in the organization's strategies and goals. Contractor companies in construction industry, that have different strategic goals and projects, always face high uncertainties in their projects; But they all have one thing in common, which it is not possible for them to implement all projects at the same time due to the limitations of resources (financial resources, human resources, equipment and machinery); Therefore they should try to achieve their strategic goals by identifying, evaluating, prioritizing and selecting the right projects by using portfolio management processes.
\end{abstract}

Mentioning this necessity, this paper aims to provide a comprehensive and realistic model for portfolio management of contractor companies in construction industry. So that each construction company with its unique strategic goals and constraints, can apply it. The proposed model has three basic steps of project identification, evaluation and selection; In the first step, all the organization's strategic goals, criteria and projects of the organization are identified, then in the second step, using a combination of AHP and SAW methods and fuzzy logic, a multi-objective decision problem to prioritizing projects based on goals (Each goal represents a group) is addressed; finally in the third stage, using the event tree (ET) method, all possible scenarios from the project's combinations (probable portfolios) are identified and according to the limitations and points of each scenario , the best scenarios are selected.

Keywords: Portfolio Management - MultiObjective Decision Making - AHP Method - SAW Method - Fuzzy Logic - Scenario Analysis

\section{Introduction}

In today's competitive and unstable world, always achieving the strategic goals of the organization through proper selection and guidance of projects and plans, is one of the most important challenges of project-oriented organizations, which necessitates the foundation of portfolio management system in such organizations. In fact, the purpose of the portfolio management system is to achieve the strategic goals of the organization by selecting and guiding the appropriate projects and plans [1]. It should be noted that, portfolio means a set of projects and plans that are managed to achieve the strategic goals of the organization. These strategic goals can be goals such as gaining maximum profit, gaining fame or entering emerging markets.

On the other hand, the employers of construction projects always face problems in choosing the right projects and due to limited resources; they cannot implement them all at the same time. Instead, they have to choose the most suitable projects, the ones that not only maximize results such as profitability, reputation, etc. but also minimize negative effects such as risks, technical problems, etc. This, in turn, increases the need for a project selection system based on a set of criteria in order to prioritize projects [2]. Therefore, choosing the right project, which is the main factor of construction 
organizations, is a vital decision that affects the future of these organizations [3].

Many organizations have tried to standardize portfolio management processes and methodologies due to the importance of portfolio management. In this regard, we can mention two important and well- known standards: 1) AXELOS ${ }^{1}$ project management standard [4] and 2) $\mathrm{PMI}^{2}$ portfolio management standard [5], which is the criterion of the model presented in this article. According to PMI, portfolio management processes are divided into two general categories: planning processes and monitoring and control processes (as presented in figure 1).

\begin{tabular}{|c|c|}
\hline \multicolumn{2}{|c|}{ Portfolio Management Processes } \\
\hline Monitoring and control processes & Planning Processes \\
-Portfolio review and reporting & Identification \\
-Strategic change & Categorization \\
& Evaluation \\
& Selection \\
& Prioritization \\
& Balance \\
\hline
\end{tabular}

Figure 1. Portfolio management processes in project-based organizations according to PMI

According to PMI Portfolio Management Standard, the purpose of the identification process is to create an up-to-date list with sufficient information of current components (projects and plans) and components to be managed through Portfolio Management. In the process of categorization, the identified components are divided into related groups to facilitate evaluation, selection, prioritization and balancing. This division is based on the strategic plan. Components in a group should have a common goal and be measurable on a basis. The evaluation process is to gather all the relevant information for the evaluation of components (projects and plans) to facilitate the selection process by comparing them. Also, in the selection process, a short list of projects is created based on the evaluation process and selection indices of the organization. In fact, in the evaluation stage, the score of each component is determined and leads to the creation of a list of portfolio components that are ready for prioritization. Finally, in the portfolio balancing process, different projects from different categories are placed in the portfolio to meet the maximum strategic goals. In fact, at this stage, the best combination of projects is selected so that strategic goals are met to an acceptable level.

\footnotetext{
${ }^{1}$ AXELOS: civil partnership of two legal natures: 1- OGC which is a British government organization and 2- Capital Plc, which is a private British consulting company.
}

It should be noted that the difference between the authors' view and PMI standard is that this standard first suggests that each project be placed in its category, then the criteria and weight criteria of each category are determined and finally the score of each project compared to the criteria of its category is specified and prioritize. According to the authors of this article, while each goal represents a group, in the categorization stage, the belonging of a project to a group cannot be considered absolute, but a project can be placed in each group with different scores. For example, a project can have score 5 in the group of profitable projects and score 2 in the group of projects aimed at gaining credit.

\section{Literature Review}

Considering the scope of the article, two categories of past researches are important here: 1) research that has focused on portfolio management methods and 2) researches that focuses on portfolio management in the construction industry. So far, extensive researches have been conducted on the selection of organizational projects and portfolio management in various industries and countries. In Finland, for example, Carlson et al. (2007) focused

${ }^{2} \mathrm{PMI}$ is a non-profit organization headquartered in the United States, but the scope of its work and activity is the whole world. 
on the selection of R\&D projects [6]. Similarly, Huang et al. (2008) studied the portfolio management of $R \& D$ projects in the public sector in Taiwan [7]. Ravanshadnia et al. investigated this issue in the construction industry and in Iranian contractor companies and presented a case model in their field of research [3]. Kozlu and Ashna Renko (2017) in Russia, also with an economic perspective, tried to manage the portfolio of investment projects in the construction industry [8].

To Voshouki, the strategic management of projectoriented organizations largely answers the question, "Which markets are more suitable for entry?" [9]. Considering the importance of choosing the right markets for the entry of organizations, choosing the right projects has been considered by many researchers in various industries. In many cases, this choice is based on a specific criterion. For example, Kongri and Boyer (1981) used net present value as a criterion as a criterion for evaluation [10]. Abbasian Jahromi et al. (2012) proposed a model for project selection using the general concept of risk management [11].

Of course, in many cases, the decision to select the organization's projects is based on multiple criteria. For example, Vergara (1993) in evaluating and selecting new projects, considered the criteria such as organizational goals, existing organizational ability, project geographical location, project specifications, legal needs and constraints, project schedule and access to resources, for decision [12]. Cheng and Hong (2005) chose the executive, managerial, economic, technical, legal and environmental criteria for selecting their projects [2].

In previous research, a wide range of methods and techniques have been used over a relatively long period of time. In 1998, Archer and Ghasemzadeh proposed a project selection format and a decisionmaking system called the project analysis and selection system [13]. Mulnar and Sanger (1998) found multi-criteria analyses appropriate for project selection issues [14]. Lin and Chen developed a fuzzy model in the same year, in which employers evaluated projects based on some of the proposed criteria using linguistic variables [15]. Cheng and Hong (2005) used the ANP method to select construction projects from an employer perspective. The ANP method is a power tool for complex decisions that exist between the elements of dependence and interequation [2]. Mahmoudzadeh et al. (2007) proposed a model based on AHP method and fuzzy TOPSIS method for project selection in order to participate in invitation to tender [16]. Carlson et al. (2007) proposed a model for selection of research and development projects [6]. In this regard, Huang et al. (2008) and Ton et al. (2010) used the fuzzy AHP method to select research and development projects [7, 17]. studying the researches, it can be understood some basic points that reviewing and completing these cases provide a comprehensive model.

1- Some studies conducted in the field of construction companies, with a case study and a criterion such as risk assessment or invest return rate, has examined the issue. However, minimizing and managing technical and economic risks or maximizing the invest return rate can be one of the strategic goals of the organization. In fact, solving this problem requires a multi-criteria assessment.

2. Most articles have tried to prioritize projects based on strategic goals, while choosing the optimal combination of projects, which is the ultimate and practical goal of organizations, has been neglected. Scenario analysis will be very useful for considering different combinations of projects (project portfolio).

3- One of the problems of the proposed models is the lack of communication between portfolio projects; In other words, in selecting new projects, they do not consider the existing projects of the organization. In fact, these models do not take into account that a single project is very different from the same project in the portfolio.

\section{3- The Proposed Model}

The proposed model in this paper includes three basic steps of project identification, evaluation and selection. Of course, it should be noted that in this classification model, balance of project portfolio and project prioritization are done automatically in the project evaluation and selection stage. In the first step, all the strategic goals of the organization, indices and projects of the organization are identified. In the second step, using a combination of AHP and SAW methods and fuzzy logic, projects are prioritized in each goal (group). In the final stage, first, with the event tree method, different scenarios of project composition are considered, and finally, according to the limitations and points of each scenario, the best scenarios are selected. In fact, each scenario represents a probable project portfolio. One of the advantages of the forthcoming model is that in selecting new projects, the existing projects of the organization are considered.

The steps of the proposed model for portfolio management in the portfolio planning stage, including identification, evaluation, project selection, along with the subset actions of each stage are presented in figure 2 in sequence and step by step. Each of these steps is described in sequence.

Step 1- Identification

In this step, it is important to identify the following: 
Step 1-1- Identifying the strategic goals of the organization: In this model, each goal represents a group. For example, projects that have the goal of economic profit or projects that are selected with the aim of entering emerging markets. Of course, unlike standards such as the PMI standard, which in the categorization stage considers the absolute belonging of a project to a group, in this model a project can be placed in each group with different scores. For example, a project can have score 5 in the group of profitable projects and score 2 in the group of projects aimed at gaining credit. This is explained in more detail in the evaluation step. Obviously, the strategic goals of each organization are different from the other organizations. To obtain sufficient information about the strategic goals of the organization, you can use methods and tools such as interviewing the organization's staff managers, distributing questionnaires among the organization's managers and studying upstream documents such as the organization's strategic document.

Step 1-2 - Identify project selection indices: It should be borne in mind that given that we are dealing with a multi-objective decision model, the indices may take different weights based on different goals. It will be much easier to understand this by looking at Figure 3. As it can be seen, the first to $\mathrm{n}^{\text {th }}$ indices have a certain weight relative to the $\mathrm{j}^{\text {th }}$ target, and these weights will change relative to the other target.

In this article and in identifying the list of project evaluation indices, the comprehensiveness of this identification has been prioritized so that different companies with different purposes can use this list. However, the relative weight of each index will vary from organization to organization. Project evaluation indices can be extracted from library resources, distribution of questionnaires and interviews with managers of construction companies, brainstorming method and Delphi method. Table 1 provides a list of proposed indices of this model, which has been obtained by carefully studying articles and books, interviewing the managers of several construction companies and holding a brainstorming session in the mentioned organizations.

As it can be seen in the table, one of the general indices considered, is the interaction of portfolio projects. In fact, in the proposed model, a single project is different from the same project in the portfolio. The criteria in this category consider the criteria resulting from the impact of one project on other portfolio projects.

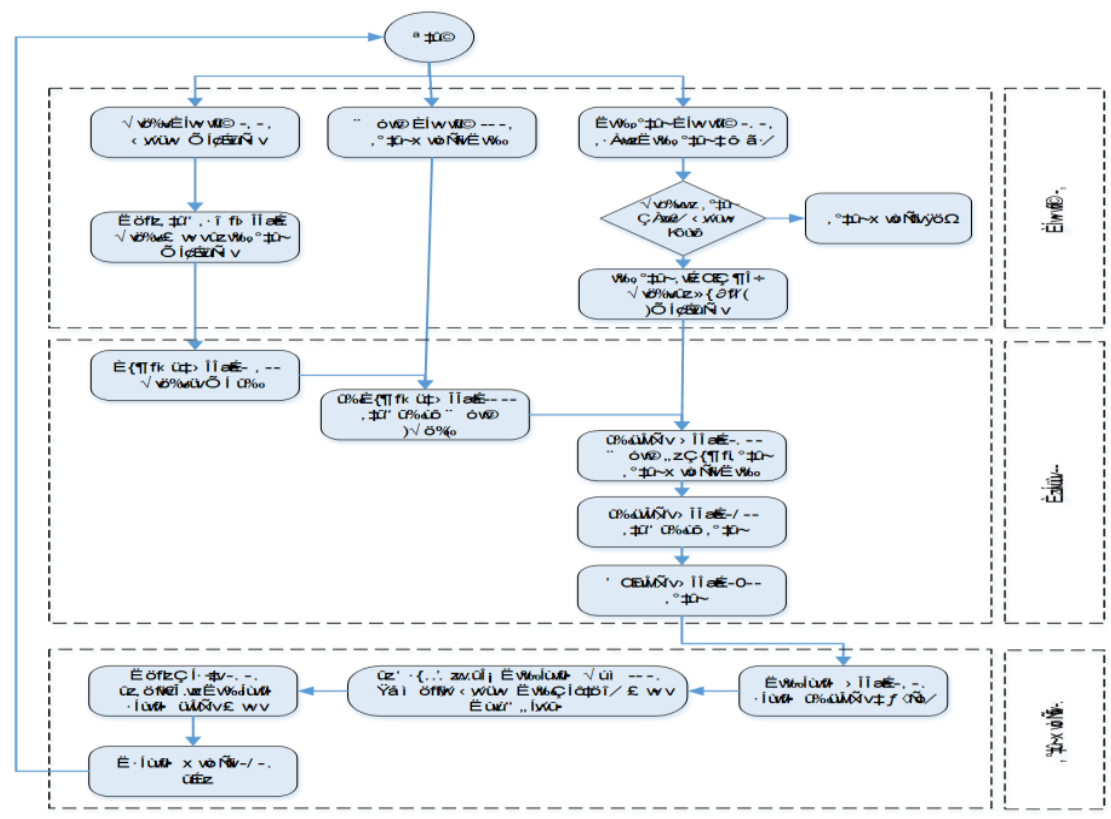

Figure 2. Steps of the comprehensive portfolio management model in the planning stage 


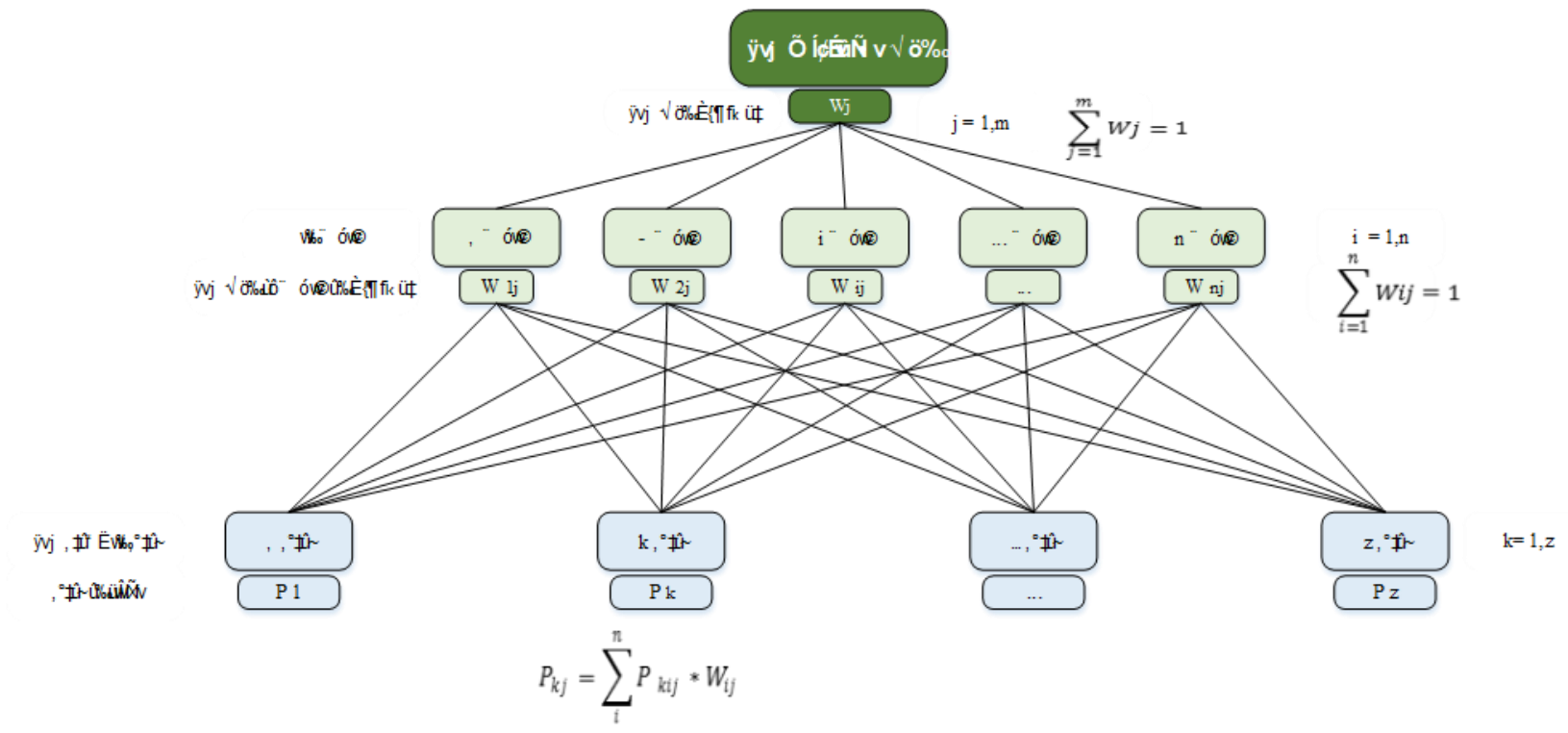

Figure 3. Multi-objective decision model

Table 1. Project evaluation indices

indices

Description

1- Executive indices

1-1-Adaptation of the project field with the company's activity field

\section{1-2- Access to required} resources

\section{1-3- Access to technology}

1-4-Manpower

1-5- Project duration
For example, a company that implements infrastructure projects, does not pay much attention to commercial or industrial projects

Access to the required resources (including financial resources, materials, machinery and equipment) enables implementation of the project.

The technology required for the project is indigenous or available from nonindigenous and foreign sources.

Execution of a project is possible when the organization has the appropriate manpower (skilled and specialized) and is able to pay their wages.

The duration of the project affects the return on investment.

2- Economic criteria

2-1-Profitability

2-2-Return on investment period

2-3-Minimum risk to profit ratio
Profitability is measured by indicators such as NPV and IRR.

At an equal profitability, a project with a shorter return on investment period is more attractive.

Risk and profit are always directly related, and in projects where more profit is expected, more risk is likely. The lower the ratio, the better the project.

3-Legal criteria

3-1- Government and official laws and standards

3-2- Contractual provisions
The implementation of the project and its prerequisites must comply with official laws and standards.

The distribution of risk in the contractual provisions between the employer and the manufacturer should be fair. 


\begin{tabular}{cc}
\hline indices & Description \\
\hline $\begin{array}{c}\text { 3-3-Employer } \\
\text { cooperation in } \\
\text { removing legal barriers }\end{array}$ & $\begin{array}{c}\text { The employer should assist and cooperate in removing legal obstacles such as } \\
\text { obtaining pre-construction permits and during construction in accordance with the } \\
\text { contract clauses. }\end{array}$ \\
\hline
\end{tabular}

4-Environmental criteria

4-1- Geographical conditions

4-2- Project location access to facilities

5-Criteria of interaction of portfolio projects

5-1-Project distance from existing projects and facilities of the organization

5-2- Similarity of project size and type with existing projects

5-3-The similarity of the project employer with the existing projects
Geographical factors such as climate, geographical difficulty (such as mountains), etc. affect the choice of project.

Projects implemented in remote and inaccessible areas (materials, equipment and manpower) run the risk of not having access to facilities.

An individual project is different from the same project in the portfolio. Criteria in this category actually consider the criteria resulting from the impact of one project on other portfolio projects.

The focus of organizational projects is a positive factor in terms of ease of distributing resources between projects.

The organization is more interested in implementing similar projects in terms of project size and type due to previous experiences,

The similarity of the employer of new projects with existing projects, in terms of the previous knowledge of the employer and the history of good previous collaborations and consequently minimizing disputes and lawsuits in the upcoming projects, is a positive and constructive factor.
Step 1-3- Identify Existing Projects and Potential Projects

As mentioned, one of the advantages of the proposed model is that in selecting new projects, the existing projects of the organization are considered. In fact, the existing projects of the organization are considered as a permanent member of the project portfolio and the addition of other potential projects (potential investment opportunities) to the project portfolio, is considered and evaluated.

\section{Step 2 - Evaluation}

The purpose of this step is to evaluate the projects and scoring each one in each group and includes the actions that are described below.

Step 2-1- Determine the Relative Weight of Each Goal

At this stage, the relative weight of the targets identified in step 1-2, is determined. For this problem, the use of AHP technique to weight the objectives is suggested and because comparisons between objectives are made using qualitative and linguistic quantities, the use of fuzzy logic in the AHP technique will be very useful. To do this, the linguistic variables of preference must first be selected for pairwise comparisons, and then membership functions must be defined for these variables. In this model, five linguistic variables have been selected and using surveys and consulting with analysts and experts to express these variables, the use of trigonometric fuzzy functions has been preferred. To compare the pair of goals, the goals are questioned and judged with the linguistic variables of preference in Table 2. These pairwise comparisons should be made by senior and middle managers in any project-oriented organization.

Table 2. Define of the comparative linguistic variables 


\begin{tabular}{|c|c|c|c|c|c|}
\hline Preference rate & $\frac{\tilde{d}}{\frac{\tilde{d}}{0}} \frac{0}{\vec{\Xi}}$ & $\stackrel{\tilde{\omega}}{\underline{\omega}}$ & 胥 & 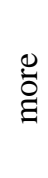 & 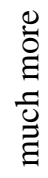 \\
\hline Preference of Objective A over Objective B. & $\square$ & $\square$ & $\square$ & $\square$ & $\square$ \\
\hline Preference of Objective A over Objective C. & $\square$ & $\square$ & $\square$ & $\square$ & $\square$ \\
\hline$\ldots$ & $\square$ & $\square$ & $\square$ & $\square$ & $\square$ \\
\hline
\end{tabular}

The limits of membership functions for the linguistic variables of preference are presented in Table 3. $a$ is the lower bound, $\mathrm{b}$ is the middle value, and $\mathrm{c}$ is the upper bound of trigonometric fuzzy functions. The diagram of the triangular membership functions of preference is also presented in Figure 4 [18].

Table 3. Define of the limits of trigonometric membership functions for linguistic variables of preference

\begin{tabular}{cccc}
\hline \multirow{2}{*}{ Linguistic variables } & \multicolumn{3}{c}{ Limits of membership functions (a, b, c) } \\
\cline { 2 - 4 } & $\mathrm{a}$ & $\mathrm{b}$ & $\mathrm{c}$ \\
\hline much less & 0.00 & 0.2 & 0.33 \\
less & 0.2 & 0.33 & 1.0 \\
equal & 0.33 & 1.0 & 3.0 \\
more & 1.0 & 3.0 & 5.0 \\
much more & 3.0 & 5.0 & 5.0 \\
\hline
\end{tabular}

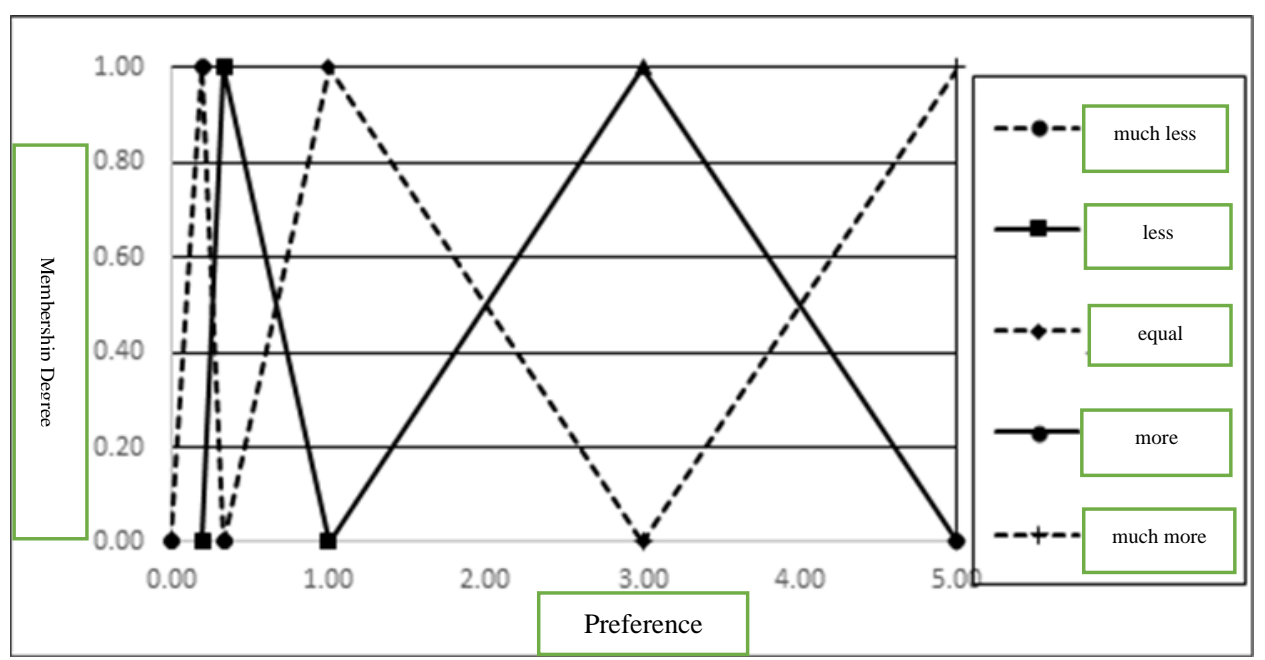

Figure 4. Graph of the triangular membership function for linguistic variables of preference

Paired judgments on the goals of the organization using the qualitative values of Table 2 can be made using a questionnaire or conducting an interview. In this model, a relative weight is set for each specialist based on the position, executive experience and level of education, and to reach a single judgment

$$
E_{i}=\sum E_{i j} W_{j}
$$

Equation (1)

The above calculations are proposed using the equation and algebra of fuzzy values of the $\alpha$-cut method; In this way, each quantity is calculated for about a quantity, expert judgments are combined in a linear equation (1); Where $E_{i}$ is the quantified quantity, $\mathrm{i}^{\text {th }}$ is the fuzzy number, $\mathrm{W}_{\mathrm{j}}$ is the weight of $\mathrm{j}^{\text {th }}$ specialist (real number) and $E_{i j}$ is the value of the $\mathrm{i}^{\text {th }}$ fuzzy quantity according to $\mathrm{j}^{\text {th }}$ expert (fuzzy number). sufficient $\alpha$-cut intervals. The above equation is converted to equation (2) for the $\alpha$-cut interval, in which the $\mathrm{E}_{\mathrm{i} \alpha}$ is the interval $\alpha$-cut of the $\mathrm{i}^{\text {th }}$ quantity 
fuzzy number $\left(E_{i}\right)$ and the $E_{i j \alpha}$ interval is the $\alpha$-cut of the $i^{\text {th }}$ quantity fuzzy number from $j^{\text {th }}$ expert's view $\left(E_{i j}\right)$.

$$
E_{i_{\alpha}}=\sum E_{i j_{\alpha}} W_{j}
$$

Equation (2)

To weigh the opinion of the interviewed manager, it is suggested to rate them based on position, managerial experience, level of education according to Table 4 [19]. Finally, the weight of each specialist

Table 4. Scoring of experts based on their characteristics

\begin{tabular}{ccc}
\hline characteristic & Classification & score \\
\hline position & Senior Manager / Consultant & 5 \\
& Middle manager / project manager & 4 \\
\hline \multirow{2}{*}{ executive experience } & More than 30 years & 5 \\
& to 30 years20 & 4 \\
& 10 to 20 years & 3 \\
\hline \multirow{2}{*}{ level of education } & 5 to 10 years & 2 \\
& Less than 5 years & 1 \\
\hline
\end{tabular}

Step 2-2- Determining the Relative Weight of Each Index in Each Group (Goal)

At this stage, the relative weight of the indicators identified in step 1-2 is determined in each group (target). This can be done using the AHP technique and paired comparisons on indices in each group (target), but due to the number of indices, paired comparisons to weigh the indices increase sharply. It is noteworthy that if there are $\mathrm{n}$ indices for weighting, $(n(n-1)) / 2$ value of paired comparison should be done. Since these comparisons are made by experts using a questionnaire, it is usually beyond the scope of these individuals to answer a large

\begin{tabular}{|c|c|c|c|c|}
\hline & Goal 1 & Goal 2 & Goal ... & Goal m \\
\hline \multicolumn{5}{|l|}{ Index 1} \\
\hline \multicolumn{5}{|l|}{ Index 2} \\
\hline \multicolumn{5}{|l|}{ Index... } \\
\hline Index $\mathrm{n}$ & & & & \\
\hline
\end{tabular}

number of questions. To solve this problem, using the SAW method, by a linear increment function to represent decision makers' preferences, greatly simplifies problem solving. Of course, in this method, it is always assumed that the preferences are independent or separate from each other. For this, the decision matrix will be in the form of figure 5 .
Figure 5. Multi-objective decision model

In this step, to eliminate the limitation of the lack of information and data, it is suggested to use the opinion and judgment of the managers of organization. Since these judgments are qualitative, it is used very low, low, medium, high, and very high linguistic variables, and also since the fuzzy logic models and evaluates these values well, then the use of fuzzy logic is suggested. The definition of these is obtained by normalizing the sum of the scores of that specialist to the sum of the scores of all specialists. linguistic variables is based on consultation with experts as well as the use of previous articles and studies [20-22]. Also, as a result of consulting with analysts and experts, the trapezoidal membership functions for linguistic variables are proposed in Table 5, in which a is the lower bound, $d$ is the upper bound, and $b$ and $c$ are the mid-range boundaries of the trapezoidal fuzzy membership function. 
Table 5. Define the limits of the fuzzy membership trapezoidal functions for linguistic variables

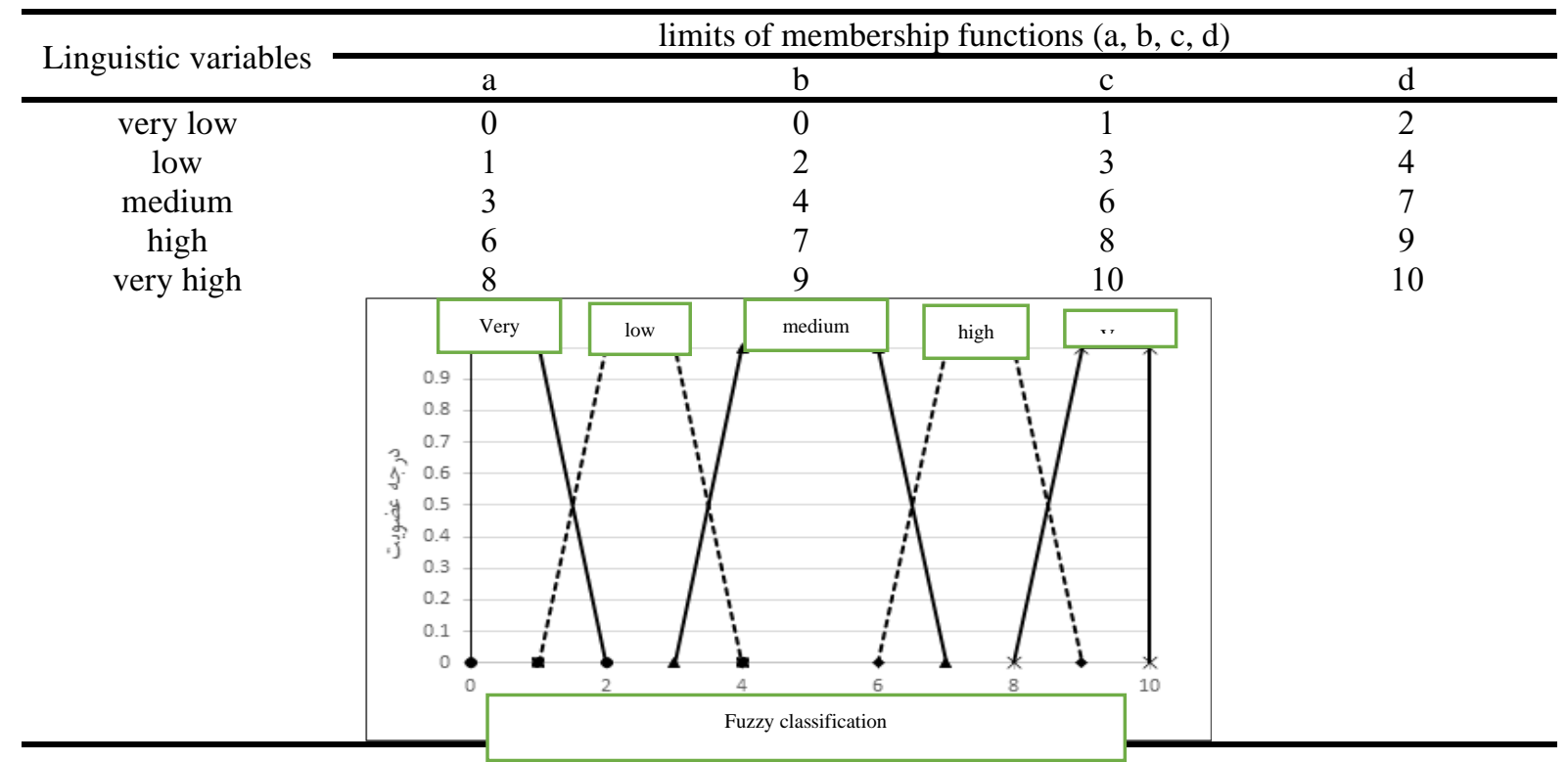

Step 2-3- Determine the Score of Each Project in Equation to The Project Selection Indices

Each project is scored according to the project selection indices, similar to the previous step, using the SAW method. Of course, some values, such as the rate of return on investment, are small that their numerical equivalent are placed in the decision matrix, and qualitative values with the corresponding fuzzy numbers of the linguistic variables (very low, low, medium, high, and very high), are small and analysed by fuzzy calculus.
Step 2-4- Determining the Score of Each Project in Each Group

If there are $m$ targets and $n$ indices are weighted for each of these targets and the number $\mathrm{z}$ of the project is scored for these indices, and the weight of the $i^{\text {th }}$ target is displayed with $\mathrm{W}_{\mathrm{i}}$ and $\mathrm{W}_{\mathrm{ji}}$ represents the weight of the $\mathrm{j}^{\text {th }}$ index relative to the $\mathrm{i}^{\text {th }}$ target, and $\mathrm{Pkj}$ is the score of the $\mathrm{k}^{\text {th }}$ project relative to the $\mathrm{j}^{\text {th }}$ index, Then the score of the $\mathrm{k}^{\text {th }}$ project in the $\mathrm{i}^{\text {th }}$ group (Pki) is calculated from the Equation 3:

$$
P_{k i}=\sum_{j=1}^{n} P_{k j} * W_{j i}
$$

(Equation 3)

Step 2-5- Determining the total score of the project

Calculation of the total score of the $\mathrm{k}^{\text {th }}$ project is obtained from Equation (4):

$$
P_{k}=\sum_{i=1}^{m} P_{k i}
$$

Equation (4)

Step 3- Select the Portfolio

At this stage, using the score of each project and considering different scenarios from the combination of projects and according to the limitations and score of each scenario, the best scenarios are selected.

Step 3-1- Determine the Different Scenarios and The Score of Each Scenario
To determine the scenarios, the event tree method is proposed. As mentioned before, if there are $n$ projects, the number of project selection modes is 2 $\wedge \mathrm{n}$ modes. Each of these selection modes is called a scenario. Understanding this will be easy by looking at the sample event tree in Figure 6 from two projects. As it can be seen, there are 4 modes to choose from. The case where each project 1 and 2 is selected, the case where only project 1 is selected, 
the case where only project 2 is selected and the case where none of the projects are selected.

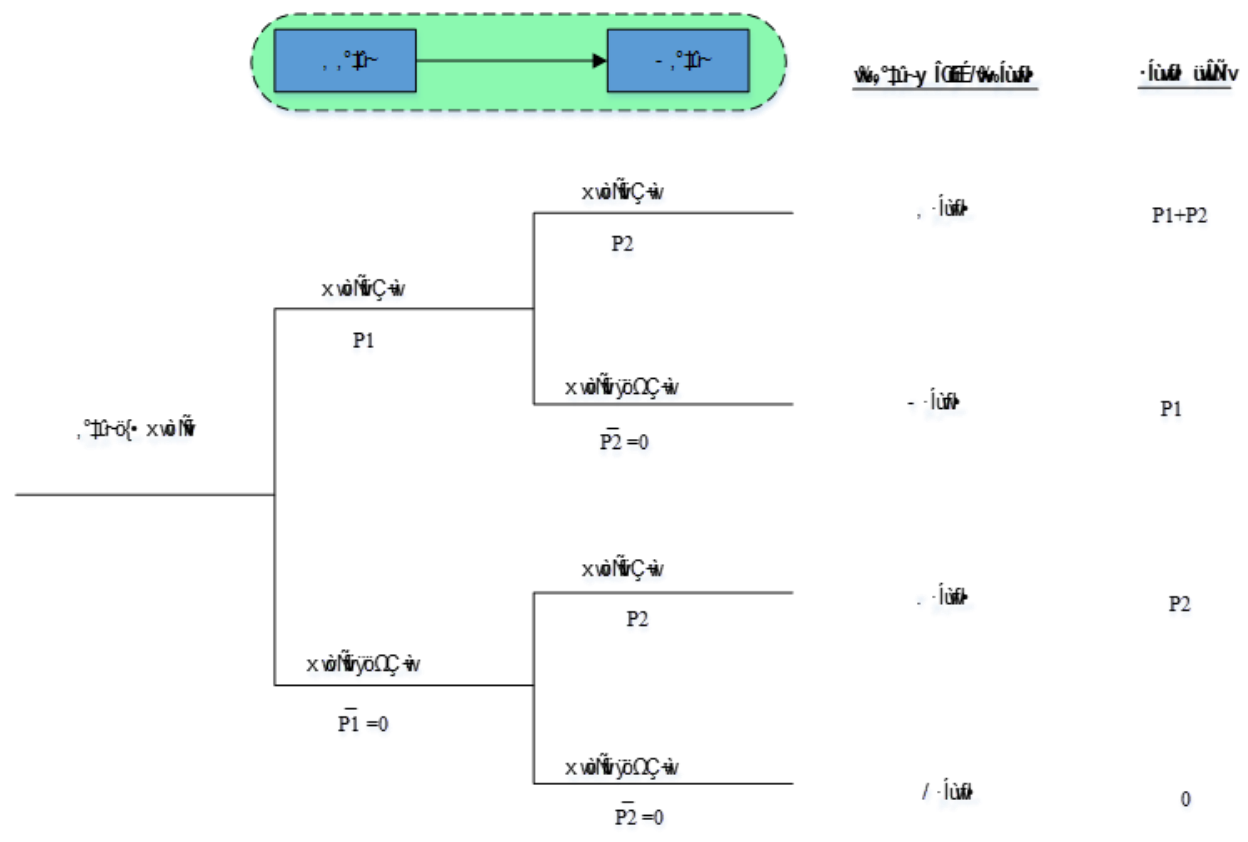

Figure 6. Sample event tree for two projects

The above tree can be generalized to $\mathrm{n}$ projects (according to the event tree in Figure 7). In such a tree $2^{\mathrm{n}}$ scenario is possible. The score of each scenario will be equal to the sum of the scores of the projects in that scenario.

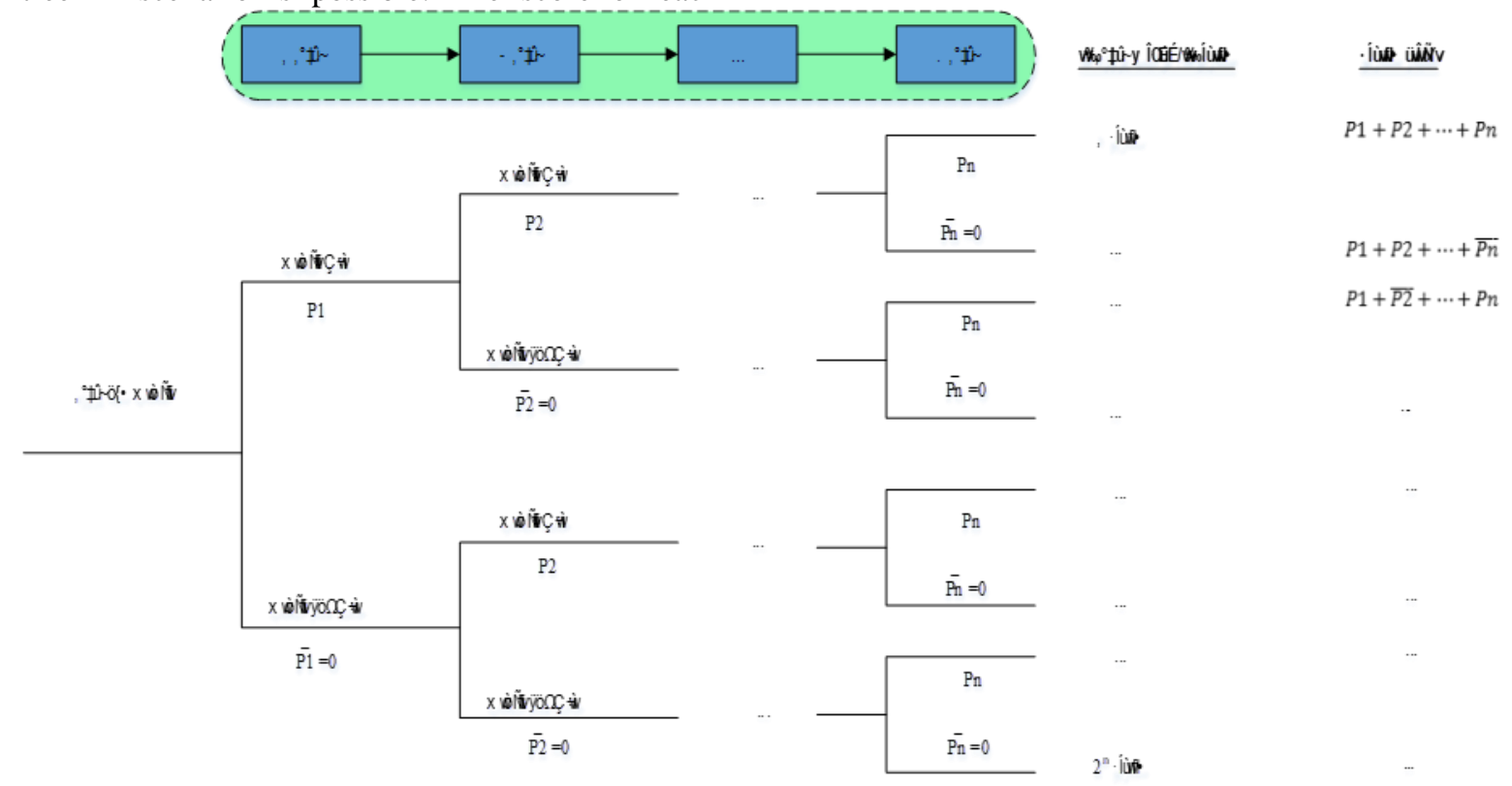

Figure 7. Event tree for different scenarios of portfolio project selection

As mentioned before, in this model, the existing projects of the organization are considered. This is important both in the evaluation stage and in the selection stage. At this stage, because the existing projects are running, there is only one mode of selection, which reduces the number of scenarios. In other words, if $\mathrm{m}$ projects exist and $\mathrm{t}$ potential project (investment opportunity) $(\mathrm{m}+\mathrm{t}=\mathrm{n})$, the number of scenarios decreases to $2^{\mathrm{t}}$.

Step 3-2- Eliminate unacceptable scenarios based on the organization's constraints

It should be noted that not every scenario with the highest score is necessarily the best scenario. Because in evaluating projects, some constraints of 
the organization in the current situation are not considered. It is possible that a scenario has a high score, but its choice is beyond the financial capacity of the organization and therefore be removed from the possible scenarios. These constraints vary from organization to organization.

Step 3-3- Prioritize the Remaining Scenarios Based on The Scenario Score

Finally, the remaining scenarios are prioritized based on the scenario score after considering the organization's constraints.

\section{Step 3-4 - Select the Best Scenario}

Finally, the top scenario that represents the best portfolio of the organization's projects is selected.

\section{Conclusion}

1- The difference between the views of the authors of this article and the PMI standard is that this standard first suggests that each project be placed in its category, then the criteria and values of each category are determined; finally, the score of each project relative to the category criteria, be selfidentified and prioritized in its category. While from the point of view of the authors of this article, each goal represents a group, in the categorization stage, belonging of a project to a group cannot be considered absolute, but a project with different scores can be placed in each group.

2- One of the advantages of the proposed model is its comprehensiveness; That is, unlike many past studies that consider project selection as a onedimensional issue, it covers decision criteria in multiple ways.

3- The proposed model in this paper is a hybrid model based on the project portfolio management process. For multi-criteria decision making, this model uses AHP method for weighting goals and SAW method for weighting project selection indices and project scoring.

4. The proposed model, unlike many articles, which only try to prioritize projects based on strategic goals, attempts to select the optimal combination of projects that is the ultimate and practical goal of the organization. In this model, scenario analysis using the event tree method is used to consider different combinations of projects (project portfolio).

5- Using fuzzy logic, this model takes into account the uncertainty caused by qualitative judgments and the lack of sufficient data.

6- Another advantage of the proposed model is considering the relationship between portfolio projects; In other words, in selecting new projects, the existing projects of the organization are considered. This relationship is considered by identifying and evaluating the indices of "interaction of portfolio projects".

\section{References}

1. Khorami Rad N., Rare MOP Portfolio Management Standard in Simple Linguistic.

2. Cheng, E.W.L. and H. Li, Analytic Network Process Applied to Project Selection. Journal of Construction Engineering and Management, 2005. 131(4): p. 459-466.

3. Ravanshadnia, M., H. Rajaie, and $\mathrm{H}$. Abbasian, Hybrid fuzzy MADM projectselection model for diversified construction companies. Canadian Journal of Civil Engineering, 2010. 37: p. 1082-1093.

4. Jenner, S., O.o.G. Commerce, and C. Kilford, Management of portfolios. 2011: Stationery Office.

5. Madic, B., V. Trujic, and I. Mihajlović, Project portfolio management implementation review. African Journal of Business Management, 2011. 5: p. 240-248.

6. Carlsson, C., et al., A fuzzy approach to $\mathrm{R} \& \mathrm{D}$ project portfolio selection. International Journal of Approximate Reasoning, 2007. 44(2): p. 93-105.

7. Huang, C.-C., P.-Y. Chu, and Y.-H. Chiang, A fuzzy AHP application in government-sponsored $\mathrm{R} \& \mathrm{D}$ project selection. Omega, 2008. 36(6): p. 1038-1052.

8. Kozlov, A. and E. Shnyrenkov, Portfolio management for investment projects in the construction industry. MATEC Web of Conferences, 2017. 106: p. 08006.

9. Veshosky, D., Portfolio Approach to Strategic Management of A/E Firms. Journal of Management in Engineering, 1994. 10(5): p. 41-47.

10. Kangari, R. and L.T. Boyer, Project selection under risk. Journal of the Construction Division, ASCE, 1981. 107(4): p. 597-608.

11. Abbasianjahromi, $H$. and $H$. Rajaie, developing a project portfolio selection model for contractor firms considering the risk factor. Journal of Civil Engineering and Management, 2012. 18(6): p. 879-889.

12. Vergara, A.J., Probabilistic Estimating and Applications of Portfolio Theory in 
Construction. 1993: University of Illinois at Urbana-Champaign.

13. Archer, N.P. and F. Ghasemzadeh, A decision support system for project portfolio selection. International Journal of Technology Management, 1998. 6(1): p. 105-114.

14. Molenaar, K.R. and A.D. Songer, Model for Public Sector Design-Build Project Selection. Journal of Construction Engineering and Management, 1998. 124(6): p. 467-479.

15. Lin, C.-T. and Y.-T. Chen, Bid/no-bid decision-making - a fuzzy linguistic approach. International Journal of Project Management, 2004. 22(7): p. 585-593.

16. S. Mahmoodzadeh, J.S., M. Pariazar, \& M. S. Zaeri, Project Selection by Using Fuzzy AHP and TOPSIS Technique. 2007.

17. Tan, Y., et al., Construction project selection using fuzzy TOPSIS approach. Journal of Modelling in Management, 2010. 5: p. 302-315.
18. Ahmadi, M., et al., Comprehensive risk management using fuzzy FMEA and MCDA techniques in highway construction projects. Journal of Civil Engineering and Management, 2017. 23(2): p. 300-310.

19. Yuhua, D. and Y. Datao, Estimation of failure probability of oil and gas transmission pipelines by fuzzy fault tree analysis. Journal of Loss Prevention in the Process Industries, 2005. 18(2): p. 83-88.

20. Abdelgawad, M. and A. Fayek, Risk Management in the Construction Industry Using Combined Fuzzy FMEA and Fuzzy AHP. Journal of Construction Engineering and Management, 2010. 136(9): p. 1028-1036.

21. Institute, P.M., A Guide to the Project Management Body of Knowledge: PMBOK Guide. 2008: Project Management Inst.

22. Abdelgawad, M. and A. Fayek, Fuzzy Reliability Analyzer: Quantitative Assessment of Risk Events in the Construction Industry Using Fuzzy Fault-Tree Analysis. Journal of Construction Engineering and Management, 2011. 137(4): p. 294-302. 